\title{
AS BIOGRAFIAS NÃO AUTORIZADAS E A ILEGITIMIDADE DA FICÇÃO
}

\author{
MELINA GIRARDI FACHIN ${ }^{1}$
}

\begin{abstract}
RESUMO: O presente artigo tem como objeto de reflexão a temática das biografias não autorizadas. A escolha de entrever o tema não apenas pelo viés jurídico, mas em diálogo com a literatura, abre a temática para novos planos. Isso porque os limites do sujeito e personagem nem sempre estão claros para definir os contornos da intimidade e do público. Do ponto de vista jurídico, o recente julgamento do Supremo Tribunal Federal, na ADI 4815, deu mais luz ao debate que não se encerra, haja vista o sentido não absoluto $\mathrm{e}$ genérico que as garantias da liberdade de expressão e de defesa da intimidade e vida privada gozam em nosso ordenamento constitucional. Com tudo considerado, partindo da premissa de que a autorização prévia para a publicação de biografias configura em si uma forma de censura, pretende-se enfrentar a temática considerando a porosidade e o arejamento que o discurso literário pode oferecer ao tema.
\end{abstract}

PALAVRaS-ChaVE: biografias não autorizadas; literatura; liberdade de expressão; intimidade.

\section{INTRODUZINDO O TEMA: AS BIOGRAFIAS ENTRE O DIREITO E À LITERATURA}

A temática das biografias não autorizadas ladeia o direito e a literatura, a realidade e a ficção, colocando em conflito a liberdade de expressão e o direito à intimidade.

Entrever a temática não apenas pelas lentes exclusivamente jurídicas, mas considerar a porosidade e o arejamento que o discurso literário pode

1 Doutora em Direito Constitucional, com ênfase em direitos humanos, pela Pontifícia Universidade Católica de São Paulo. Visiting researcher da Harvard Law School. Mestre em Filosofia do Direito Constitucional pela Pontifícia Universidade Católica de São Paulo. Professora da Faculdade de Direito da Universidade Federal do Paraná (UFPR). Autora de diversas obras e artigos na seara do Direito Constitucional Internacional e Direito Internacional dos Direitos Humanos. Advogada sócia da banca Fachin Advogados Associados. Membro do Conselho Permanente de Direitos Humanos do Estado do Paraná e da Comissão de Direitos Humanos da OAB/PR. Curitiba, PR, Brasil. CV Lattes: http://lattes.cnpq.br/1368334568714375. E-mail: melinafachin@gmail.com. 
oferecer ao tema, coloca a questão em novos planos. Pensar o direito a partir da literatura não é apenas pensar - ou seja, as maneiras de conexão entre esses dois discursos não é discussão relegada ao plano abstrato -, exsurgem daí consequências práticas.

A análise dessas diversas formas de pensar o direito a partir da literatura é, em realidade, a apreciação de modos plurais e porosos de incidência do fenômeno jurídico.

No caso das biografias, não se trata de acondicionar a literatura no direito, mas compreender seu sentido e manifestação literária, para, em diálogo construtivo, chegar a uma solução jurídica mais adequada.

Esse diálogo é bastante interessante porque as biografias divisam o imaginário da realidade e caminham, na zona limítrofe, entre o real e a fantasia. Não são uma radiografia da realidade porque sempre pressupõem a mediação do literato sobre o dado que se reflete ${ }^{2}$. No caso das biografias não autorizadas essa zona limítrofe se agudiza³ .

Assim sendo, os limites do sujeito e da personagem nem sempre estão claros para definir os contornos da intimidade e do público. Todavia, o direito é chamado a dar uma resposta sobre o tema e precisar a cerca entre o jardim e a praça (Saldanha, 1993).

Muitos podem se indagar o que resta ainda falar do tema se o Supremo Tribunal Federal - em julgamento recente ${ }^{4}$ - já decidiu justamente nesse sentido.

2 A hermenêutica é nesse sentido tomada como "básico estar-em-movimento do Ser que constitui a sua finitude e a sua historicidade e, por isso, inclui o conjunto da sua experiência no mundo" (Gadamer, 1997, p. 15).

3 “Confesso que quando vejo na capa de um livro 'biografia autorizada', eu não abro o livro. Não tem valor: a biografia autorizada é uma fraude porque está dizendo que o biógrafo está escrevendo aquilo que o biografado gostaria que ele escrevesse". Relato do escritor José Murilo de Carvalho colacionado na obra de Anderson Schreiber (2011) sobre o tema abaixo citado.

4 "Por unanimidade, o Plenário do Supremo Tribunal Federal julgou procedente a Ação Direta de Inconstitucionalidade (ADI) 4815 e declarou inexigível a autorização prévia para a publicação de biografias. Seguindo o voto da relatora, ministra Cármen Lúcia, a decisão dá interpretação conforme a Constituição da República aos arts. 20 e 21 do Código Civil, em consonância com os direitos fundamentais à liberdade de expressão da atividade intelectual, artística, científica e de comunicação, independentemente de censura ou licença de pessoa biografada, relativamente a obras biográficas literárias ou audiovisuais (ou de seus familiares, em caso de pessoas falecidas). Na ADI 4815, a Associação Nacional dos Editores de Livros (ANEL) sustentava que os artigos 20 e 21 do Código Civil conteriam regras incompatíveis com a liberdade de expressão e de informação. O tema foi objeto de audiência pública convocada pela relatora em novembro de 2013, com a participação de 17 expositores". Notícia veiculada no site: < http://www. 
Em primeiro lugar, convém destacar que estamos entre aqueles que veem no Poder Judiciário um dentre os muitos importantes atores da interpretação constitucional5. No que toca ao plano estatal, à luz dessa tônica colaborativa, há de se passar de uma análise "intra-institucional" para uma "inter-institucional", consoante explica Conrado Hübner Mendes (2008)6 ao defender que as diferentes instâncias deliberativas estatais dialoguem em prol de solução que melhor conforte os direitos humanos no caso concreto.

Assim, em que pese ter decidido a questão, com o reforço dos efeitos do controle de constitucionalidade, não encerrou o debate7. Primeiro porque carece de legitimidade democrática ao assim fazê-lo isoladamente. Todo o aparelho de Estado é responsável e deve se somar na realização da dignidade da pessoa humana, sem se sobrepor um ao outro, cada qual compreendendo sua relevância colaborativa ${ }^{8}$. Segundo, porque essa ideia de encerramento (de última palavra) é incompatível com o dinamismo político-jurídico que se traduz no processo de tomada de decisões, ainda mais daquelas vinculantes que podem, e devem, se beneficiar dos diálogos interinstitucionais.

Ao fechar uma porta - se é que assim se pode admitir -, o julgamento no Supremo Tribunal Federal abriu algumas outras. Isso porque a liberdade

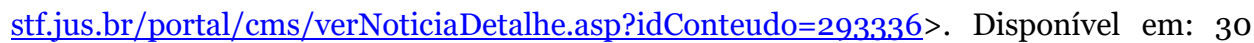
set. 2015 .

5 "Limitar a hermenêutica constitucional aos intérpretes corporativos significa empobrecimento dela. A ampliação do círculo de intérpretes é apenas uma consequência da necessidade de integração da realidade no processo de interpretação, assim, o autor prega a democratização da interpretação constitucional. A constituição precisa estar ligada à realidade social e, para tanto, é necessário que haja a incorporação das ciências sociais, por métodos de interpretação voltados para atendimento do interesso público e do bem-estar geral" (Häberle, 1997, p. 105).

6 Defende o autor, a partir desse ponto, a "separação de poderes deliberativa". (Mendes, 2008, p. 261).

7 A ótica a informar os entes estatais e as instituições políticas na resolução de altercações em prol da prevenção do sofrimento e da proteção da dignidade humana é aquele dialógico e não concorrencial, conforme expõe Conrado Hubner Mendes: "Podemos pensar em dois tipos-ideais de interação, a partir da oposição entre duas atitudes puras: a deliberativa (que fala e escuta, com o objetivo de persuasão), e a adversarial (que fala para se impor). O primeiro está mais exposto publicamente ao argumento, mais aberto ao reconhecimento do diálogo, e mais disposto ao desafio deliberativo" (Mendes, 2008, p. 219).

8 "Num Estado Social, modelo adotado pela Carta Brasileira de 1988, o Poder Judiciário é exigido a estabelecer o sentido ou a completar o significado da legislação constitucional e ordinária que já nasce com motivações distintas às da certeza jurídica, o que o dá o papel de 'legislador implícito'. Dessa maneira, a agenda da igualdade redefine a relação entre os três Poderes, adjudicando ao Poder Judiciário funções de controle dos poderes políticos" (Krell, 2002, p. 98). 
de expressão e os direitos de personalidade são essenciais ao Estado Democrático de Direito, mas não podem ser tomados de modo absoluto.

Do ponto de vista jurídico, para discussão do tema, não há como partir de qualquer outra premissa se não aquela autorizada pela Constituição, a saber: A autorização prévia para a publicação de biografias configura em si uma forma de censura.

É justamente daí que também partimos para, ladeando a questão dos direitos em jogo, contribuir com algumas notas provocativas ao debate.

\section{UMA DAS PONTAS: LIBERDADE DE EXPRESSÃO}

Se há uma relação umbilical entre o estado democrático de direito e os direitos humanos e fundamentais - no que toca à liberdade de informação e de expressão essa conexão é ainda mais estreita.

Liberdade de expressão e democracia são conceitos essencialmente imbricados, não há democracia possível sem que haja plena possibilidade de exercício de expressão.

A liberdade de expressão, como princípio, é abrangente, englobando a expressão da atividade intelectual, artística e científica, a liberdade de comunicação, de imprensa, de reunião e de discussão, além da liberdade de receber informações de interesse público (Machado, 2002).

É fruto, justamente, do movimento liberal iluminista que marca a primeira onda do constitucionalismo. Exemplo disso é que, nos Estados Unidos, a Primeira Emenda à Constituição já determinava que o Congresso não poderia votar leis que cerceassem a liberdade de palavra ou imprensa. A Declaração Francesa dos Direitos do Homem e do Cidadão já dispunha sobre a livre comunicação das ideias e das opiniões. Desde então está no âmago das preocupações fundamentais do Estado Constitucional.

$\mathrm{Na}$ história constitucional pátria, a liberdade de expressão consta desde o primeiro documento constitucional, tendo sido formalmente suprimida apenas da Constituição do Estado Novo - ainda que materialmente o tenha sido em alguns outros momentos de nossa história. Todavia, é a partir da Constituição de 1988, que a liberdade de expressão retoma sua materialidade ressignificada e é colocada em evidência. 
Evidentemente, a ideia de livre expressão não atende mais à concepção liberal que teve o mérito de positivar, ganhando no constitucionalismo contemporâneo novos contornos.

Nesse contexto, compreender a liberdade de expressão como direito fundamental restringível é também essencial ao Estado Democrático de Direito, uma vez que é passível de abuso (Barroso, 2003). Não se trata, de modo algum, de impor censura prévia, mas de arcar com as consequências decorrentes do uso abusivo de tal direito, sendo escolha do próprio constituinte originário abarcar reservas ao princípio - único poder habilitado para assim o fazê-lo, remarque-se.

A liberdade de expressão também encontra eco na expansão do bloco de constitucionalidade de nossa Constituição, nos principais documentos e tratados internacionais de direitos humanos. Haja vista o passado ditatorial recente, é importante marco do sistema interamericano de direitos, a saber:

A jurisprudência do sistema tem explicado que o marco jurídico interamericano outorga esse alto valor à liberdade de expressão porque se baseia em um conceito amplo da autonomia e da dignidade das pessoas, e porque considera tanto o valor instrumental da liberdade de expressão para o exercício dos demais direitos fundamentais, quanto sua função essencial dentro dos regimes democráticos 9 .

\section{A OUTRA PONTA: VIDA PRIVADA E INTIMIDADE}

Ao lado do princípio da liberdade de expressão, o outro polo desse debate, coroado pela esfera da vida privada e da intimidade, também se apresenta como corolário da Democracia e essencial ao paradigma do Estado Democrático de Direito.

A proteção do indivíduo, sua imagem, honra, privacidade e intimidade frente aos demais e ao Estado são também pressupostos da democracia. Ter uma esfera recôndita preservada dos interesses públicos não está à margem da Constituição, mas justamente por ela tutelada. Não

9 Relatório especial do Sistema interamericano sobre liberdade de expressão, disponível em: $\quad$ https://www.oas.org/pt/cidh/expressao/docs/publicaciones/20140519\%20-\%20 PORT\%20Unesco\%20-20Marco\%20Juridico\%20Interamericano\%20sobre\%20el\%20 Dere cho\%20a\%2ola\%20Libertad\%20de\%20Expresion\%20adjust.pdf $>$. Sobre o tema ver ainda: CIDH. Justiça e inclusão social: Os desafios da democracia na Guatemala. Capítulo VII: A situação da liberdade de expressão na Guatemala, § 419. Disponível em: <http://www.cidh.oas.org/countryrep/Guatemala2003sp/capitulo7.htm>. Caso "A Última Tentação de Cristo" (Olmedo Bustos e outros) Vs. Chile. Transcritos em: Corte I.D.H., Caso "A Última Tentação de Cristo" (Olmedo Bustos e outros) Vs. Chile. Sentença de 5 de fevereiro de 2001. Série C, $N^{\circ} 73$ 
por acaso tais direitos encontram eco constitucional, também desde os primórdios do constitucionalismo moderno.

Ainda que a privacidade e a intimidade tenham surgido como conquista e privilégio da burguesia, no seu redimensionamento contemporâneo, figuram como importantes direitos para proteger o indivíduo do exercício arbitrário dos poderes públicos e privados.

No âmbito interno, no mais das vezes, o tema é recepcionado pela ótica dos direitos da personalidade - o que em nada retira a sua fundamentalidade. Em interlocução com o direito civil, a proteção efetiva dos direitos humanos, dos direitos fundamentais, passa também pela reflexão sobre os nominados direitos da personalidade, pois, esta reclama tutela unitária que tenha seu cerne na dignidade da pessoa humana ${ }^{10}$.

Esse caráter garantista da proteção à esfera da vida privada é reiterado - para além do texto constitucional - por diversos outros documentos internacionais de direitos humanos que agasalharam a temática dos direitos de personalidade. Sobretudo, pela sua tônica, o Sistema Europeu de Direitos Humanos tem dado grande espaço de reflexão a esses direitos ${ }^{11}$.

\section{OS DOIS LADOS: CESSÕES RECÍPROCAS E LIMITADORAS}

Ambos os direitos fundamentais aqui enfocados - liberdade de expressão e intimidade - justamente por pertencerem a essa categoria de fundamentalidade se sujeitam, como qualquer outro direito da espécie, a avaliações que, à luz das circunstâncias concretas, os fazem ora prevalecer, ora ceder passagem a outros interesses que, também voltados à realização e

10 Assim, afirma a professora Maria Celina Bodin de Moraes: “À identificação taxativa e ao desmembramento dos direitos da personalidade se opõe a consideração de que a pessoa humana - e, portanto, sua personalidade - configura um valor unitário, daí decorrendo o reconhecimento, pelo ordenamento jurídico, de uma cláusula geral de tutela a consagrar a proteção integral da personalidade, em todas as suas manifestações, tendo como ponto de confluência a dignidade da pessoa humana, posta no ápice da Constituição Federal de 1988" (1994. p. 174).

11 Eis o art. $8^{\circ}$ da Convenção Europeia de Direitos Humanos que tem tido importante interpretação evolutiva por seu intérprete autorizado: "Art. $8^{\circ}$ - Qualquer pessoa tem direito ao respeito da sua vida privada e familiar, do seu domicílio e da sua correspondência. Não pode haver ingerência de autoridade pública no exercício deste direito senão quando esta ingerência estiver prevista na lei e construir uma providência que, numa sociedade democrática, seja necessária para a segurança nacional, para a segurança pública, para o bem-estar econômico do país, a defesa da ordem e a prevenção das infrações penais, a proteção da saúde ou da moral, ou a proteção dos direitos e das liberdades de terceiros". 
desenvolvimento da pessoa humana, mostram-se merecedores de igual proteção pela ordem jurídica.

A depender das escolhas juspolíticas fundamentais e sua configuração na hipótese real considerada, um cederá a cena para o outro. Estamos também entre aqueles que compreendem que mais do que coordenação de interesses há uma escolha que se faz, sempre à luz do caso concreto, a fim de atender a "uma exigência de justiça, ou equidade, ou alguma outra dimensão de moralidade" (Dworkin, 2007, p. 24).

Quando se coloca em enfoque a problemática das biografias não autorizadas, portanto, percebe-se que não se pode dar ao direito à intimidade caráter absoluto, sob pena de se ferirem outros direitos de tamanha relevância - como fez o art. 20 do Código Civil -, razão de sua flagrante inconstitucionalidade.

Afirma o dispositivo legal:

Salvo se autorizadas, ou se necessárias à administração da justiça ou à manutenção da ordem pública, a divulgação de escritos, a transmissão da palavra, ou a publicação, a exposição ou a utilização da imagem de uma pessoa poderão ser proibidas, a seu requerimento e sem prejuízo da indenização que couber, se lhe atingirem a honra, a boa fama ou a respeitabilidade, ou se se destinarem a fins comerciais.

Há aqui a imprópria prevalência abstrata, pasteurizadora da realidade e absoluta da preferência - pelo legislador infraconstitucional -, de um bloco de direitos sobre outro.

Não se pode, todavia, cair no outro extremo.

Liberdade de expressão e direitos de personalidade, portanto, convivem em uma dinâmica relação de reciprocidade limitadora.

Diante do caso concreto, e dos caminhos que se abrem, quando a luz da situação fática determinar, uma opção há de ser feita. Não estamos entre aqueles que acreditam que há maior ou menor incidência de direitos. Não há ponderação, concordância prática ou sopesamento de tais valores, com o objetivo de apurar sua importância e assim determinar a medida de concretização de cada um deles (Alexy, 2001). Há uma seleção, adequada do ponto de vista das opções constituintes, à luz das circunstâncias do caso, a ser tomada.

O tema das biografias não autorizadas, como em outros casos difíceis (Dworkin, 1975), coloca em concorrência princípios - neste caso da 
liberdade de expressão e da intimidade - que, considerando as peculiaridades fáticas e as opções jurídico-políticas da comunidade na qual se insere, levarão a prevalência de determinado princípio que melhor responderá ao caso concreto. Um cederá e outro prevalecerá (Dworkin, 1975).

\section{UMA "ESTRELA" DE MUITAS PONTAS: OS SUJEITOS ENVOLVIDOS}

Uma circunstância decisiva nesse embate da prevalência dos direitos é a publicidade dos sujeitos envolvidos. É certo que a medida da privacidade de indivíduos de vida pública sujeita-se a parâmetro menos rígido do que os de vida estritamente privada. Isso decorre, naturalmente, da necessidade de autoexposição, de promoção pessoal ou do interesse público na transparência de determinadas condutas.

Para além do caráter público do sujeito biografado, a forma como o biografado se comportava em relação a sua própria intimidade é também preponderante. Esse foi o fator preponderante no caso da biografia não autorizada do jogador de futebol Garrincha, a saber:

Na biografia intitulada "Estrela Solitária - Um brasileiro chamado Garrincha" houve diversas alusões aos relacionamentos extraconjugais do jogador, bem como ao seu desempenho sexual, sobretudo no capítulo chamado "A Máquina de Fazer Sexo". Ocorre, no entanto, que Garrincha, quando ainda em vida, nunca omitiu os relacionamentos extraconjugais. Também não fazia questão de desmentir ou omitir as especulações acerca de sua vida sexual. Assim, a atitude do jogador em relação à sua própria intimidade foi fator a ser analisado ${ }^{12}$.

Já, por outro lado, o comportamento de figuras públicas recatadas, como, por exemplo, toda a polêmica acerca do livro sobre a vida de Roberto Carlos, suscita ainda mais dúvidas sobre a quem pertence a história de determinado sujeito: "Biografia é história e a história não pertence às pessoas - história é de domínio público" (Candeia, 2007).

Diante do exposto, seria válido considerar que há figuras públicas mais públicas que outras? Ou mesmo intimidades mais íntimas?

12 Parte do voto do Desembargador Sergio Cavalieri Filho, transcrito no acórdão proferido pelo Superior Tribunal de Justiça no âmbito do REsp 521.697/RJ, Rel. Min. Cesar Asfor Rocha, 16.2.2006, colacionado na obra de Anderson Schreiber sobre o tema. 
Na sociedade em que o espaço mais recôndito de nossa intimidade vira espetáculo nas redes sociais, mesmo para aqueles que nem figuras públicas podem ser consideradas, fica ainda mais difícil valer-se desse critério como fiel da balança nas deliberações ${ }^{13}$.

Todas essas questões são profundamente pertinentes para traçar os limites da zona cinzenta de onde acaba a intimidade e onde começa a liberdade de expressão.

A única certeza que se tem é a da obsolescência de nosso ordenamento civil pátrio que continua pugnando que a vida privada da pessoa natural é inviolável, conforme art. 21 do Código Civil. "Não é", afirma categoricamente Anderson Schreiber (2011).

\section{AUTOTUTELA DA CENSURA VERSUS POSSIBILIDADE DE RESTRIÇÕES}

Preterir a liberdade de expressão por meio da exigência de autorização prévia é censura praticada em autotutela e, por todo o histórico político-institucional do país, é inadmissível.

A disposição legal assentada no art. 20 do Código Civil representa escolha inconstitucional de interesses por parte do legislador, que sobrepõe bens constitucionais concorrentes e isonômicos. A opção do legislador, tomada de modo apriorístico e desconsiderando as peculiaridades dos personagens e dos casos, para além da ignorância da liberdade de informação, deve ser afastada em exercício de interpretação constitucional conforme, e foi justamente o que fez o STF.

Corroborar com a constitucionalidade do art. 20 é admitir uma única resposta certa e anterior a todas as questões envolvendo a liberdade de expressão e a intimidade dos biografados. Para além disso, inaugurar-se-ia um incompatível espaço próprio de absolutização da intimidade, confrontante com o modelo constitucional adotado.

A possibilidade de censura, todavia, não significa impossibilidade de restrições.

\footnotetext{
13 Cumpre aqui registrar relevante crítica feita da ocasião do IV CIDIL, após a exposição do presente texto, pelo Professor José Calvo González. Segundo sua intervenção, levar em conta o comportamento do indivíduo para tal fim seria, em termos análogos, considerar que uma profissional do sexo seria mais "violável" fisicamente - o que seria absurdo, concluiu o ilustre Professor (Calvo González, 2008).
} 
O que se coloca como inconstitucional e impensável é a autotutela da censura prévia. O impedimento da divulgação da biografia por meio de órgão da jurisdição suplanta a censura privada por parte do biografado e ganha contornos possíveis dentro dos parâmetros do Estado Democrático de Direito.

A restrição à publicação é excepcional, mas existe. Pode e deve ser feita pelo Poder Judiciário. Ainda que tenhamos críticas ao papel de ativo protagonista ao que o Judiciário se alçou na atualidade, apenas ele pode dar conta de responder essa aporia. Os particulares fazem da tutela de seu direito uma arbitrariedade em desforço próprio, e o legislador, ao tutelar com abstração e generalidade, não consegue ver as particularidades de cada caso. Resta, assim, ao Judiciário, quando posta a questão, deliberar.

Nesse caso, apenas a repercussão de um dano irreparável e superior àquele produzido com a proibição de publicação de biografia não autorizada - não só ao biógrafo que tem seu trabalho preterido, mas também à sociedade, que perde em direito de acesso à informação e tem a liberdade de expressão, princípio salutar da democracia, maculado. Neste caso não se trata de censura, mas sim uma das escolhas dos direitos constitucionais incidentes, com ônus argumentativo justificador necessário.

Não basta o direito operar na base do quem fala o que quer, ouve o que não quer. Existem limites prévios do que pode ser falado - todavia, esses limites não estão ao dispor e alcance das vontades particulares e dependem - no estado Democrático de Direito - de uma instância intermediadora do conflito. Caso contrário, estar-se-ia chancelando a emergência de um novel direito fundamental que é o de causar dano a outrem - esse sim absoluto, porque ilimitável -, desde que assumido o seu preço.

\section{A ADI 4815: O COMEÇO DO DEBATE}

Dada toda a polêmica envolvendo as biografias não autorizadas, foi ajuizada no Supremo Tribunal Federal Ação Direta de Inconstitucionalidade (ADI 4815), sob a relatoria da Ministra Carmen Lúcia, questionando a constitucionalidade dos arts. 20 e 21 do Código Civil.

A relatora posicionou-se:

De fato, a interpretação mais imediata e literal dos preceitos legais questionados faz a publicação ou 
veiculação das obras biográficas de qualquer natureza depender de prévia autorização dos indivíduos biografados, ou de seus descendentes, no caso de pessoas falecidas. Porém, tal exigência, ainda que motivada pelo propósito de proteção dos direitos da personalidade, configura restrição legal manifestamente desproporcional aos direitos fundamentais à liberdade de expressão e ao acesso à informação, consagrados pela Constituição da República (art. $5^{\mathrm{o}}$, inciso IV, IX e XIV, art. 220, $\S \S 1^{\circ} \mathrm{e}$ $\left.2^{\mathrm{O}}\right)$.

A incompatibilidade do art. 20 espalha-se na preferência de valores constitucionais prima facie, em abstrato, olvidando do caso concreto e preterindo de modo completamente desarrazoado outros princípios de grande relevância albergados pela Constituição de 1988.

Nos votos dos diferentes ministros que acompanharam a relatora, à unanimidade, podem se recolher motivos que tornam a carga axiológica da liberdade de expressão preferente e de especial atenção:

i. O primeiro deles é, justamente, a motivação histórica, decorrente do passado enfadonho brasileiro que, por meio da Ditadura Civil-Militar, censurou ferrenhamente a liberdade expressão. Trata-se da maturação de nosso Estado Democrático, assentou a Corte.

ii. Associou-se a liberdade de expressão à garantia da democracia, pois somente a mais ampla liberdade de expressão permitiria aos cidadãos o acesso à informação e a ideias divergentes sobre os mais diversos assuntos, de modo a formarem suas próprias opiniões e participarem ativamente da atividade política da comunidade.

iii. Fez-se referência à liberdade de expressão como princípio essencial à autonomia privada e à busca pela verdade ${ }^{14}$.

$\mathrm{O}$ direito à liberdade de expressão desponta, assim, no pronunciamento judicial, como de posição preferencial perante os demais direitos fundamentais pela sua relação de causa-efeito com a democracia. $\mathrm{O}$ que, diga-se de passagem, não é novidade na decisão do STF, que na ADPF 130, acerca da lei de imprensa, já assim apontou.

14 Ver a íntegra dos votos. Disponível em: <http://www.stf.jus.br/arquivo/cms/noticia NoticiaStf/anexo/ADI4815LRB.pdf> . Acesso em: 10 out. 2016. 
Esse conjunto de ideias vai, de certo modo, ao encontro da tradição norte-americana do free market of ideas (Gordon, 1997), em que, no caso das biografias, aponta que apenas as inverdades são, de alguma forma, passíveis de limitação jurídica e jurisdicional.

A prevalência preferente da liberdade de expressão se coaduna com a nossa tradição constitucional, todavia sofre o risco de cair no paradoxo de confirmar o comportamento que o STF justamente admitiu como inconstitucional, qual seja: a prevalência de um valor abstrato que se sobreponha ante outro de igual respeito e consideração. Há, a nosso ver, de se perquirir melhor a distinção entre incidência preferente e uma presunção juris tantum de incidência preferente. A sutileza da distinção ganha contornos práticos relevantes.

Assim que não há discordância com a conclusão apresentada pelo julgamento, mas esse argumento que passou, em muito, desapercebido na fundamentação deve ser visto com muita cautela. Infelizmente muitas vezes comemoramos decisões como resultados, sem atentar para a ratio decidendi.

\section{À GUISA DE CONCLUSÃO: PARA FOMENTAR O DEBATE}

Ter qualquer espécie de posição preferencial, além de não se sustentar no texto constitucional que tutela também a intimidade, o direito de resposta e a repercussão danosa, não pode desbocar em direitos que não admitam limitações ou conduzir a uma hierarquia constitucional inexistente.

A liberdade de expressão não é absoluta e encontra limites no exercício de outros direitos fundamentais. A inexigibilidade de prévia autorização por parte dos biógrafos e editoras não apenas não afasta eventual direito à indenização ou mesmo o exercício do direito de resposta, como igualmente não afasta, em circunstâncias excepcionais, medidas mais rigorosas, como inclusive o que se deu no conhecido caso "Ellwanger"15, quando em causa a publicação de obras de teor antissemita.

Eis aqui um primeiro ponto conclusivo que gostaria de abordar à luz do direito e literatura, criticamente em relação ao julgamento do STF. Não

15 Habeas corpus n. 82424, julgado pelo Supremo Tribunal Federal em 17/o9/2003. 
há um processo contínuo de elaboração conjunta dos diversos escritores que constroem discursivamente o Direito. Os Ministros não dialogam, o STF não dialoga com as suas decisões anteriores - aqui em especial cite-se o caso da lei de imprensa e de Sigfried Ellwanger, que tratam de temáticas conexas. Não temos uma única narrativa, mas diversos contos que dividem o resultado da decisão promulgada.

Os aplicadores devem agir de forma coerente sobre as decisões passadas e as presentes, como se prosseguissem na escrita dessa nossa obra coletiva que é o Direito. Assim sendo, ignorar isso é descurar do caráter histórico e transindividual da construção jurídica ${ }^{16}$.

De fato, o tema das biografias não autorizadas dá ensejo a grandes discussões no âmbito jurídico. Quando dois direitos fundamentais são colocados em conflito, a solução nunca é fácil e sempre traz sacrifícios, não só abstratamente, mas em concreto também, porque repercute em pessoas. Apesar de tudo isso, é preciso que tais decisões sejam tomadas, de modo a garantir a integridade da democracia e da Constituição - o que nem sempre significa prevalecer a liberdade de expressão.

Pode-se dizer sem hesitação que a exigibilidade de autorização prévia para a publicação de biografias é desproporcional e desarrazoada, configura verdadeira censura determinada pelos entes privados, que buscam, a rigor, interesses próprios. Todavia, retirar daí a preferência abstrata da liberdade de expressão não cabe na nossa moldura constitucional. Repousa nesse ponto o segundo e último argumento conclusivo sobre o tema à luz do direito e da literatura.

Dizer, portanto, que ficção tudo supera, que a literatura das biografias sempre prevalecerá sobre o direito à intimidade configura absolutismo que justamente conflita com uma postura mais aberta do direito que se busca por meio das lentes literárias. Ver o direito como um texto aberto e permeável que esse movimento em direção à literatura nos ensina não combina com posturas absolutizantes como essa.

\footnotetext{
16 “A segurança e a estabilidade que se propõem não estarão na certeza ou na previsibilidade da decisão em si, em se saber o que vai ser julgado, mas na certeza de que os Ministros julgarão de acordo com a integridade, ou seja, comprometidos a uma coerente e defensável visão dos direitos e deveres que as pessoas têm, o que é possível na adoção da doutrina do stare decisis que envolve que a vinculação dos tribunais ao passado significa que podem aplicar um precedente, revogá-lo ou distingui-lo, mas nunca ignorá-lo" (Barboza, 2014, p. 188).
} 


\section{REFERÊNCIAS}

ALEXY, Robert. Teoria de los Derechos Fundamentales. Madri: Centro de Estúdios Políticos y Constitucionales, 2001.

BARBOZA, Estefânia Maria de Queiroz. Escrevendo um romance por meio dos precedentes judiciais: uma possibilidade de segurança jurídica para a jurisdição constitucional brasileira. $A \& C-$ Revista de Direito Administrativo \& Constitucional, Belo Horizonte, ano 14, n. 56, p. 177-207, abr./jun. 2014.

BARROSO, Luis Roberto. Colisão entre liberdade de expressão e direitos da personalidade: critérios de ponderação; interpretação constitucionalmente adequada do código civil e da lei de imprensa. RTDC - Revista Trimestral de Direito Civil, v. 4, n. 16, p. 59-102, out./dez., 2003.

CALVO GONZÁLEZ, José. Libertad de expresión artística. ¿Equilibrio de Derechos, o Derechos en equilibrio? Dikaiosyne - Revista semestral de Filosofía práctica (Grupo Logos: Filosofía, Derecho y Sociedad. Centro de Investigaciones Jurídicas. Universidad de Los Andes. Mérida. Venezuela), Año XI, n. 21 p. 7-46, Julio-Diciembre 2008. Disponível em: $<$ http://www.saber.ula.ve /bitstream/123456789/26385/1/articulo1.pdf $>$. Acesso em: 30 set. 2015.

CANDEIA, Karla. Um novo censor nas paradas. Observatório da imprensa, ed. 433, 18/05/2007. Disponível em: <http://observatoriodaimprensa. com.br/caderno -da-cidadania/um-novo-censor-nas-paradas $>$. Acesso em: 30 set. 2015 .

DOWKIN, Ronald. Decisions in hard cases should be and are based on arguments of principle. Hard Cases Harvard Law Review, n. 6, n. 88, p. 1057-1109, Apr. 1975.

DWORKIN, Ronald. Levando os direitos a sério. 2. ed. São Paulo: Martins Fontes, 2007.

GADAMER, H. G. Verdade e método. Rio de Janeiro: Vozes, 1997.

GORDON, Jill. John Stuart Mill and the "Marketplace of Ideas". Social Theory and Practice, n. 23, v. 2, p. 235-249, Summer 1997.

HÄBERLE, Peter. Círculo aberto dos intérpretes da Constituição. Porto Alegre: Sérgio Fabris, 1997.

KRELL, Andreas Joachim. Direitos sociais e controle judicial no Brasil e na Alemanha: os (des)caminhos de um direito constitucional "comparado". Porto Alegre: Sergio Antonio Fabris, 2002.

MACHADO, Jónatas E. M. Liberdade de expressão: dimensões constitucionais da esfera pública no sistema social. Coimbra: Coimbra, 2002.

MENDES, Conrado Hübner. Direitos fundamentais, separação de poderes e deliberação. Tese (Doutorado em Ciência Política) - Universidade de São Paulo - USP, São Paulo, 2008. Disponível em: <www.teses.usp.br L.../TESE CONRADO HUBNER MENDES.pdf $>$. Acesso em: 20 dez. 2012. 
MORAES, Maria Celina Bodin de. Recusa à realização do exame de DNA na investigação de paternidade e direitos da personalidade. In: BARRETO, Vicente. A nova família. Rio de Janeiro: Renovar, 1994. p. 169-194.

SALDANHA, Nelson. O jardim e a praça: o privado e o público na vida social e histórica. São Paulo: Edusp, 1993.

SCHREIBER, Anderson. Direitos da personalidade. São Paulo: Atlas, 2011.

Idioma original: Português

Recebido: 10/02/16

Aceito: 15/06/16 